\title{
Cement concrete and concrete-polymer composites: two merging worlds
} A report from 11th ICPIC Congress in Berlin, 2004

\author{
D. Van Gemert ${ }^{1)}$, L. Czarnecki ${ }^{2)}$, P. Łukowski ${ }^{2)}$, and E. Knapen ${ }^{1)}$ \\ 1) Katholieke Universiteit Leuven, Belgium \\ 2) Warsaw University of Technology, Poland
}

\begin{abstract}
The search for durable and sustainable construction materials inspires the developments in the world of cement concrete, as well as in the world of concrete-polymer composites. Both worlds recognize, strive for and accept each other's contribution to the synergic effects that are realized by the combination of classical building materials and polymers. A better knowledge of materials behaviour, especially in the field of admixtures, and a better understanding of curing processes allowed the development of highly performing mineral or modified mineral concretes, mortars and grouts. CPC-science becomes an invaluable element in the development of sustainable construction materials.

ICPIC organises practitioners and scientists, dealing with concrete-polymer composites in all industrial fields, but with emphasis on construction industry. The 11th International ICPIC Congress took place in Berlin, 2-4th June 2004. New trends and evolutions have been presented and discussed. The highlights of the Congress, and the synergies that emerge from the congress for the construction world in combination with cement concrete, will be presented and discussed in the paper.
\end{abstract}

Keywords: polymer composites, performance, durability, modelling, synergy.

\author{
Elke Knapen \\ Katholieke Universiteit Leuven \\ Kasteelpark Arenberg 40 \\ 3001 Heverlee \\ Belgium
}

Email: Elke.Knapen@,bwk.kuleuven.ac.be

Tel: +32 (0) 16321678 


\subsection{Introduction}

The International Congresses on Polymers in Concrete aim to create a synergy between researchers and practitioners all over the world, dealing with the spectacular possibilities of concrete-polymer composites. During the three decades from the first congress in London in 1975 to the 11th congress in Berlin in 2004 [1], there have been dramatic changes in the way of thinking about industrial processes and the approach and evaluation of new and innovative materials.

In the industrialised world, the sixties and seventies of last century were characterised by an unlimited belief in new and modern materials and techniques. The use of polymers was considered to be a sign of progress and modern attitude in construction and in industry. Glass fibre reinforced polyester panels, polyester resin and polyester mortar were known as inexpensive plastics. Epoxy glues were used as highly performing adhesives in concrete prefabricated applications, epoxy resins were used as binders in chemically resistant coatings and flooring systems as well as in electrical insulation applications, acrylic resins were used in machine frame construction. Research aimed at developing new, improved polymers was continuously done, and new applications for polymers and concrete-polymer composites CPC were constantly developed. In building industry, the use of polymers gradually extended from concrete crack injection to repair mortars for concrete and stone, consolidation of masonry, repair of timber structures, not to forget all finishing, piping and waterproofing materials. At that time, building materials science was an underdeveloped field of construction industry and science. So, the extended use of pure polymers led to inherent chemical and physical incompatibility problems, mechanical malfunctioning and durability problems.

In the early seventies, the oil crises learned that mineral oil as a cheap basis for polymer production was not longer available. It was also found that oil reserves were limited. As a consequence, all uses of polymers were questioned. First of all, the waste of fossil oil for energy production, and secondly, the massive use of polymers as alternative for classical building materials such as concrete, masonry, timber and metals. The use of polymers became part of a search for durable or sustainable construction materials. Polymers should only be used in these areas were their specific properties are needed. In combination with classical construction materials a synergic effect can be obtained.

This evolution led to new applications of polymer modified repair mortars for concrete, stone and masonry. Pure polymer concrete building components can be partly replaced by CPC, as in flagstones and building panels. A better knowledge of materials behaviour, especially in the field of admixtures, and a better understanding of curing processes allowed the development of highly performing mineral or modified mineral concretes, mortars and grouts. CPC-science is now an invaluable element in the development of sustainable construction materials.

The topics of the 11th ICPIC Congress reflect new approaches and findings in CPC-research. The micro-structural models are subject to changes, polymers in solution are subject of research and might become valuable alternatives for polymer emulsions and polymer dispersions, biological effects are taken into account in degradation processes but might also be turned into positive performance contributions. Sustainability, and reversibility and recycling as subtopics of it, dominate the developers' minds. The scientific program of the congress was managed by BAM, the Federal Institute for Materials Research and Testing (Germany), in collaboration with Warsaw University of Technology (Poland) and Katholieke Universiteit Leuven (Belgium). 


\subsection{Importance of polymers in European construction industry}

During the European Colloquium Orgagec '02 organised by Laboratoire Central des Ponts et Chaussées in Poitiers, France, in March 2003, M. de Longcamp presented figures of consumption of polymers in the European Union (15 members; 330 million inhabitants) in 2000 [2]. Some data for the largest components in polymer consumption are listed in Table 1.

On average about $8 \%$ of polymer consumption concerns thermosets, the rest being thermoplasts [3]. In 2003, 7350000 tons or $18.5 \%$ of the total market of polymers in Western Europe (European Union, Norway and Switzerland) were used in building and construction industry [4]. The relation to other industries is shown in Table 2.

Table 1: European consumption of polymers in construction

\begin{tabular}{|l|l|l|}
\hline Application field & Type & Consumption \\
\hline Textiles in architecture & Polyester/glass & 28000 tons \\
& PVC/polyester & 100000 tons \\
& Carbon/Kevlar & Not significant \\
\hline Highway noise barriers & System concrete-timber & $\pm 30 \%$ \\
& Recycled plastic & $\pm 2 \%$ \\
& Transparent plastics & $\pm 5 \%$ \\
& Concrete & $\pm 10 \%$ \\
& Timber & $\pm 15 \%$ \\
& Metal & $\pm 10 \%$ \\
& Vegetation screens & $\pm 10 \%$ \\
& & Total $1.970 .000 \mathrm{~m}^{2}$, \\
& & $15 \%$ increase/year \\
\hline Impermeable membranes & PVC & 200000 tons \\
& PE (HD + LD) & 250000 tons \\
& EP, PU, UP resins & 50000 tons \\
& SBS, APP bitumen modif. & 88000 tons \\
\hline Road paintings & Liquid, hot melt, strips & 280000 tons \\
\hline Tubing for optical fibres & PEHD & 200000 tons (2001) \\
& & 600000 tons (exp. 2010) \\
\hline Tubes for sewers, gas, water... & PVC, PE, PP, UP & 2761000 tons \\
\hline Concrete modification & & 486000 tons \\
\hline
\end{tabular}

Table 2: Relative share of polymers in construction to other industries in 2003 [4]

\begin{tabular}{|l|c|}
\hline Industry & Polymer consumption [\%] \\
\hline Packaging & 37.2 \\
\hline Construction & 18.5 \\
\hline Large Industry & 5.8 \\
\hline Electrical/Electronic & 8.5 \\
\hline Other Household/Domestic & 20.1 \\
\hline Automotive & 8 \\
\hline Agriculture & 1.9 \\
\hline
\end{tabular}


However, if the consumption of polymers is compared to the consumption of other construction materials, its relative share is only about $1 \%$, Table 3 .

The share in weight is only about $1 \%$, but in financial turnover polymers represent more than 10 $\%$ of construction industry. It is expected that in about 10 to 15 years polymers in construction will be the prime part of the polymer market.

The amount of polymers, used in concrete-polymer composites, is only a minor part in polymers for modification of concrete, which also include water reducing agents (121500 tons of superplasticizer in EU in 1998). However, due to the synergic action between polymers and the cementitious matrices, the impact on performance of building materials largely overpasses the weight ratio.

Table 3: Relative share of building materials in EU-construction industry (year 2000)

\begin{tabular}{|l|c|c|}
\hline Construction material & Consumption [tons] & Ratio [\%] \\
\hline Concrete and cement based & 503000000 & 71 \\
\hline Tiles and bricks & 73000000 & 10 \\
\hline Timber & 54000000 & 7 \\
\hline Iron and steel & 24000000 & 3 \\
\hline Stone, quarry & 16000000 & 2 \\
\hline Asphalt and bitumen & 16000000 & 2 \\
\hline Polymers & 6850000 & 0,97 \\
\hline Flat glass & 5200000 & 0,73 \\
\hline Mineral wool & 2000000 & 0,3 \\
\hline Copper & 1300000 & 0,2 \\
\hline Aluminium & 900000 & 0,1 \\
\hline
\end{tabular}

\subsection{Concrete-Polymer Composites}

Polymer modified concrete or mortar is a composite material consisting of two solid phases: the aggregates which are discontinuously dispersed through the material and the binder which itself consists of a cementitious phase and a polymer phase. According to the volume fraction of the polymer in the binder phase the material shifts from PCC, i.e. polymer cement concrete, to PC, i.e. polymer concrete.

In the case of PCC, the binder consists of a polymer-cement co-matrix. The polymer is added to the fresh mixture as an emulsion or as redispersible polymer powders. During hardening and curing, cement hydration and polymer film formation take place resulting in a co-matrix in which polymer film is intermingled with cement hydrates. A special group of materials in which polymers are used in combination with concrete is PIC, polymer impregnated concrete. Here, the polymer is injected in the pores of the hardened concrete and forms a second matrix if the pores are interconnected throughout the material. The hardened concrete may be a cement concrete, a PCC or a PC. The properties of the composite material derive not only from its constituents, but there is also a synergic effect.

Applications of concrete-polymer composites cover a wide range of applications in different industries: concrete and stone repair materials; polymer modified cement adhesives; prefabricated 
building components like flag stones, tubes, panels; porous and eco-concrete; machine base elements; insulators for electrical and chemical industry; fibre reinforced materials: chemically resistant materials; industrial floors; recycling of polymer wastes; liquid applied waterproofing materials ...

\subsection{Integrated model for microstructure building in polymer cement concrete [5]}

Cement hydration in polymer modified material is influenced by the presence of the polymer particles and polymer film in the fresh state, during hydration as well as in the hardened state. The properties of the fresh mixture are influenced to a large extent by the surfactants, present at the surface of the polymer particles. The cement particles are better dispersed in the mixture and a more homogeneous material is formed. The hydration of the cement is reflected in the strength evolution of the material.

The influence of the polymer modification is twofold. Due to the polymer and the surfactants, a retardation of the cement hydration can be noticed. This is especially visible in the compressive strength of the mortar beams. On the other hand, due to the film formation or due to the interaction between the cement hydrates and the polymer particles, the tensile strength of the binder matrix as well as the adhesion strength between the aggregate and the binder increase. This is especially seen in the flexural strength of the mortar beams. The results are presented in [6], [7] and [8].

From the results of the mechanical tests, compressive strength and flexural strength, conclusions towards film formation mechanism and especially towards the time at which film formation takes place may be drawn. Considering the compressive and flexural strength after 7 days dry curing, together with the reduction, respectively increase of the strength in relation to the strength of the unmodified mortar, an increase in flexural strength is noticed, although the cement hydration is retarded when the polymer-cement ratio is increased (lower compressive strength). This points at the existence, already at an early stage of curing, of a polymer film or at least at the interaction between polymer particles and cement particles. However, the incapacity of the modified "porous" mortar specimens to overcome the large shrinkage stresses after 7 days or 28 days moist curing indicates that the continuous polymer film is not yet formed in the case of water saturated conditions. No influence of the polymer modification on the flexural strength is noticed in the case of standard cured and water cured samples as long as no dry curing period is applied.

So, one may conclude that at high relative humidity, the influence of polymer modification on the flexural strength at short term is limited. From the moment a dry curing period is introduced, a polymer film starts to build up through the binder phase and an increase in flexural strength is measured with increasing $\mathrm{p} / \mathrm{c}$ ratio. The influence on the flexural strength of the retardation of the cement hydration is compensated by the presence of the polymer film. When long-term behaviour is considered, a maximum of flexural strength is established around $15 \% \mathrm{p} / \mathrm{c}$ ratio.

The mutual influences between the cement hydrates and the polymer particles and film are incorporated in an integrated model of structure formation. The model is based on the three-step model as proposed by Ohama [9], but stresses the positioning of the mechanisms on the time scale and the interaction between the different components. The findings are supported by images taken with an environmental scanning electron microscope at the University of Dresden [10].

The formation of the polymer film can take place from the moment two polymer droplets have sufficient energy to overcome the repulsion forces originating from the surfactants. In other words, 
if the temperature is high enough to cause sufficient Brownian motion, or if additional forces are working on the liquid layer around the polymer droplets, such as capillary forces or water withdrawal by further cement hydration, two droplets can come close to each other and can coalesce into each other and a polymer film is formed. This process simultaneously can take place with the cement hydration mechanism, especially in the case of dry curing conditions. Therefore, partial or full encapsulation of the cement hydrates is possible, which retards the hydration process. The different steps of the conclusive model are presented in Fig. 1 to 4.

Immediately after mixing, the cement particles and polymer particles are dispersed in the water. The first hydration of the cement takes place, which results in an alkaline pore solution. This is indicated as step 1, Fig. 1.

The second step is presented in Fig. 2. A portion of the polymer particles is deposed on the surface of the cement grain and the aggregate. The polymer-cement ratio determines the amount of polymers present in the pore solution and present at the aggregate surface. Part of the polymer particles may coalesce into a continuous film. This preferably takes place at the surface of the cement hydrates where extra forces are exerted on the polymer particles due to the extraction of water for cement hydration. The polymer film can partly or completely envelop a cement grain, which results in a retardation or even a complete stop of the hydration of the cement grain.

The following step, Fig. 3 consists of cement hydration, polymer flocculation and possibly polymer coalescence into a film. The processes that take place depend on the curing conditions. If no dry curing period, i.e. curing at a lower R.H., is included, the overall film formation is retarded and the influence on the properties of the fresh mixture is limited at this stage. If a dry curing period is included, polymer film formation takes place during this step, which influences the cement hydration process as well as the strength development at early ages. In the bulk liquid phase, hydrate precipitations are present, which form a combined inorganic and organic product. The fractions of the different types of product formed depend on the polymer/cement ratio used. The polymer fractions included in these hydration products do not contribute to the strength development of the specimen [11].
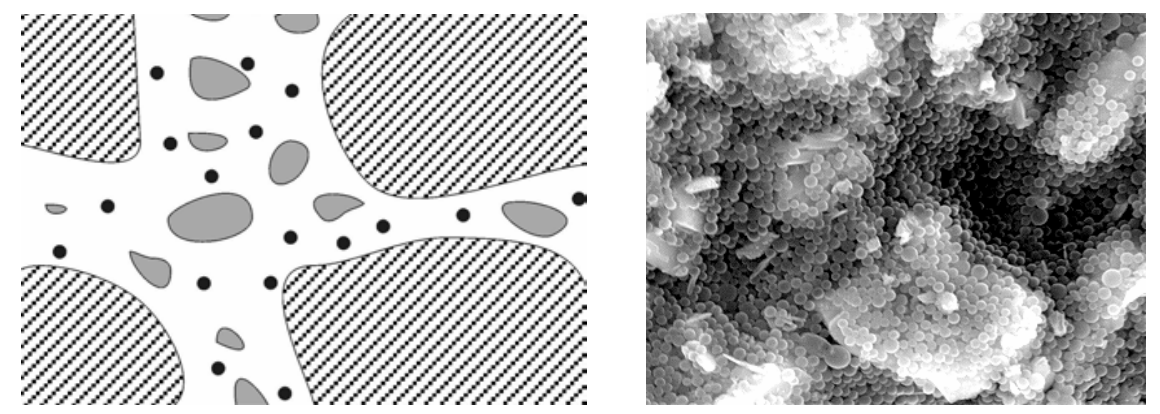

Figure 1. Step 1, immediately after mixing, aggregates, cement particles, polymer particles and mixing water - small ettringite needles are formed. 

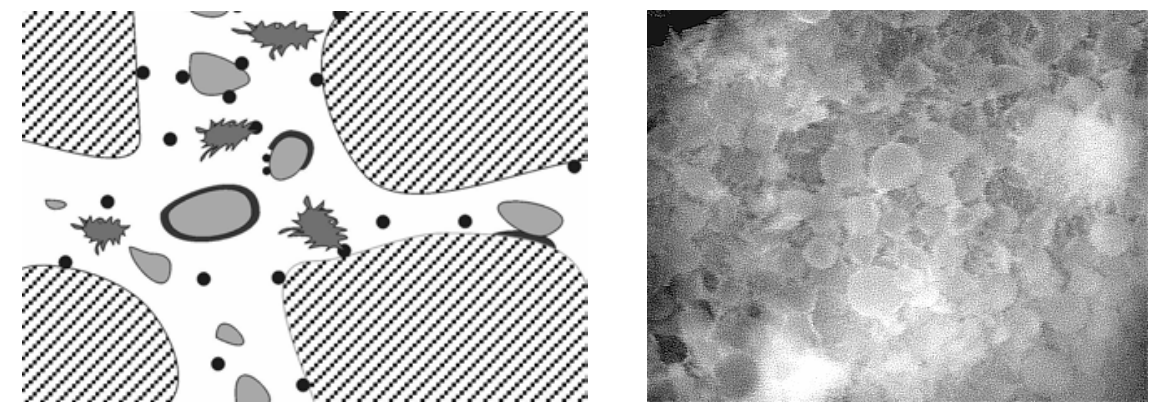

Figure 2. Step 2, after mixing, the polymer particles interact with the cement particles and the aggregates. In the case a dry curing period is introduced, a continuous film may be formed polymer particles flocculate together, on restricted places, no coalescence has taken place at this stage.
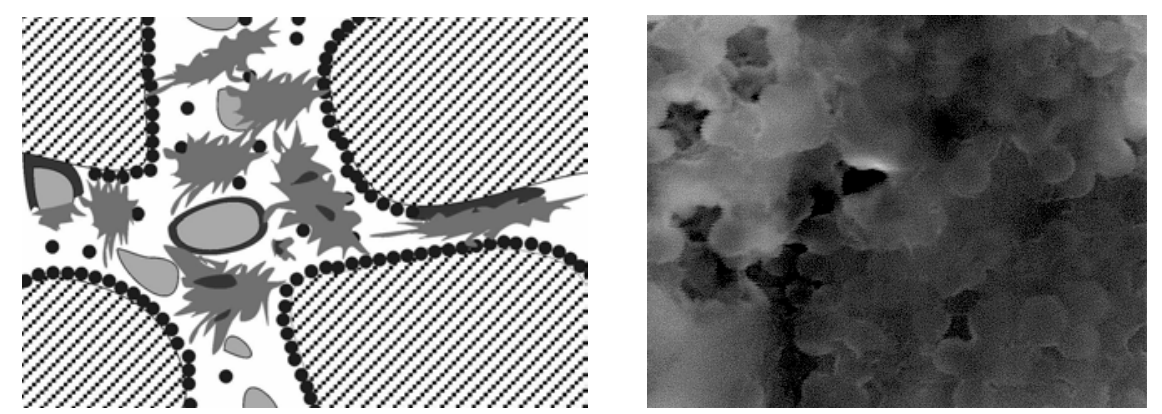

Figure 3. Step 3, cement hydration proceeds, polymer film formation starts on specific spots polymer particles coalesce together into a continuous film.

The final step, Fig. 4 includes further hydration and final film formation. Through the cement hydrates, a continuous polymer film forms as water is further removed from the pore solution. The part of the polymer particles, that is still present in the dispersion, is restricted to the capillary pores and at the interface of the aggregates and the bulk polymer-cement phase. It is this part which contributes the most to the elastic and final strength properties. The continuity of the polymer phase through the binder matrix is more pronounced in the case of a higher polymercement ratio. In the case the MFT of the polymer dispersion is much more elevated than the curing temperature, the polymer particles may not coalesce into a continuous film, but remain as closely packed polymer particles. 

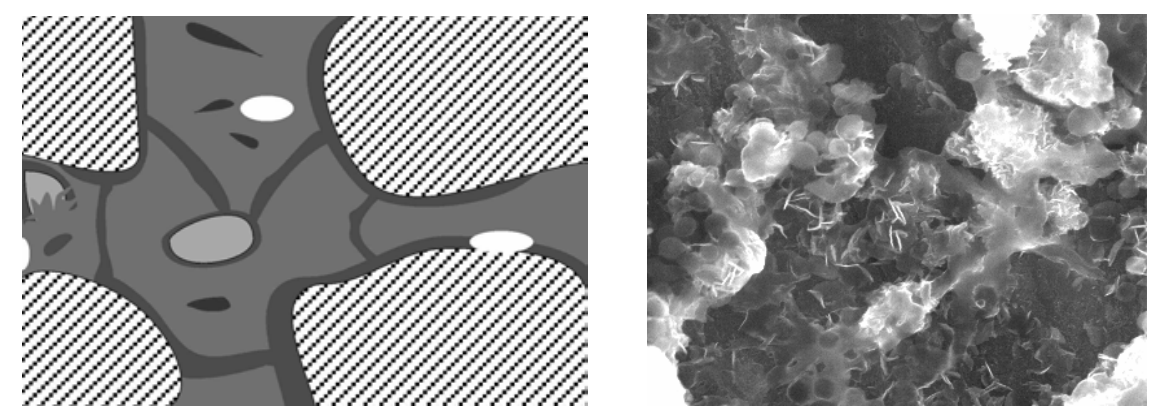

Figure 4. Final step, cement hydration continues, the polymer particles coalesce into a continuous film - cement particles are hydrated.

The use of the integrated Beeldens-Ohama-Van Gemert model can be illustrated with the different curing conditions. From the results it is concluded that optimal conditions towards the strength development are a wet curing period followed by a dry curing period. The longer the moist and water curing period is, the higher the final flexural strength will be if shrinkage is prevented and if a curing period at lower R.H. is introduced. This means that first cement hydration takes place and only limited film formation. Therefore, the polymer particles remain in the pore solution and a larger amount of polymer particles will be incorporated into the continuous film, which is formed in the final stage. If the drying period is introduced earlier in the process, the film formation will start sooner, i.e. before and simultaneously with the cement hydration, resulting in enlarged encapsulation of the cement hydrates as well as incorporation of the polymer phase in the hydration product precipitated from the pore solution.

The relative humidity of the surrounding atmosphere has a large influence on the film formation and especially on the drying rate. The higher the relative humidity of the surrounding atmosphere, the lower the drying rate becomes. This influences to a large extent the film forming temperature of the dispersion. The lower the drying rate, the lower the amount of energy needed for the polymer particles to coalesce into a continuous film. The MFT is reduced with a reduced drying rate. Tests indicated that even at laboratory circumstances, i.e. $20^{\circ} \mathrm{C}$, a SAE dispersion with a MFT of $32^{\circ} \mathrm{C}$, could form a continuous film, as long as the drying rate was low enough.

The cement hydration is also influenced by the fact that water is longer retained due to the presence of the surfactants at the surface of the polymer particles. This results in a better dispersion of the polymer particles and the cement hydrates, but also retards the cement hydration. The influence increases with increasing $\mathrm{p} / \mathrm{c}$-ratio.

This model accentuates two important changes towards the original model of Ohama. First, a relation to the time scale of the different processes is made. When a dry curing period is included, cement hydration and polymer film formation coincide and encapsulation of cement particles is possible. Further, the formation of an interstitial phase, consisting of inorganic and organic precipitates in the bulk phase, is pointed out. This is important towards an optimal benefit of polymer modification since the polymers present in this phase are contributing less to the final properties of the material. The optimum conditions come forward from these findings, i.e. a long period of water or moist curing (up to 28 days) during which the cement hydrates develop followed by a curing period at lower relative humidity, promoting the polymer film formation. 


\subsection{Polymers as microcrack stopper in cement concrete [12]}

At the Building Materials Institute of Technical University of Dresden the new technology of environmental scanning electron microscopy is being used in combination with a specially developed loading device, that allows to apply tensile load on small specimen inside the microscope chamber. They are now able to show the effects of microcrack propagation in the loaded specimen. Opening increase of microcracks can be followed and investigated from a width of about $300 \mathrm{~nm}$ up to about $20 \mu$, allowing to study the behaviour of all the particles, which are cut by the crack. Especially the polymer action as microcrack stopper can be observed by visualization of the stretching of the polymer particles over the microcrack.

The power of this innovative investigation technique can be illustrated with some pictures of a microcrack in a polymer cement concrete, with $\mathrm{p} / \mathrm{c}=30 \%$, at consecutive crack widths during tensile loading. Not only the crack bridging effect can be studied, but also the moment of rupture of the polymer bridges can be observed.

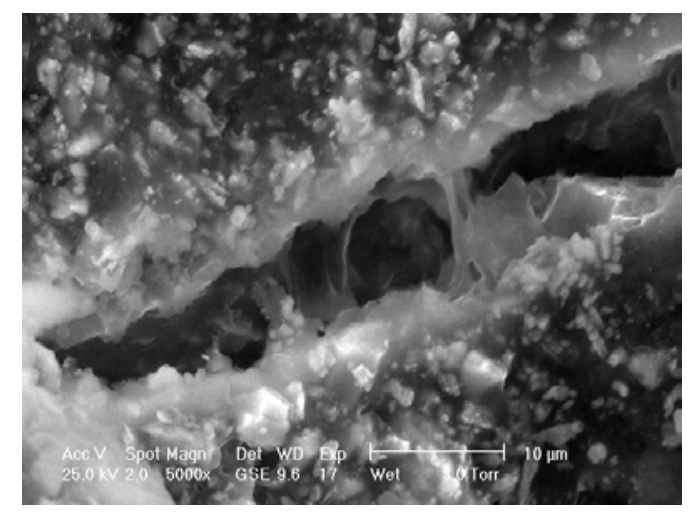

Figure 5. Crack bridging behaviour of polymers in concrete, maximum crack width $\sim 9 \mu \mathrm{m}$

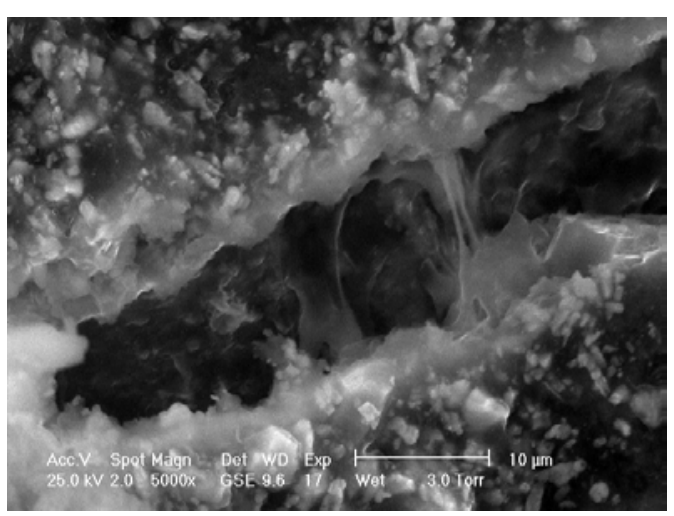

Figure 6. Crack bridging behaviour of polymers in concrete, maximum crack width $\sim 11 \mu \mathrm{m}$ 


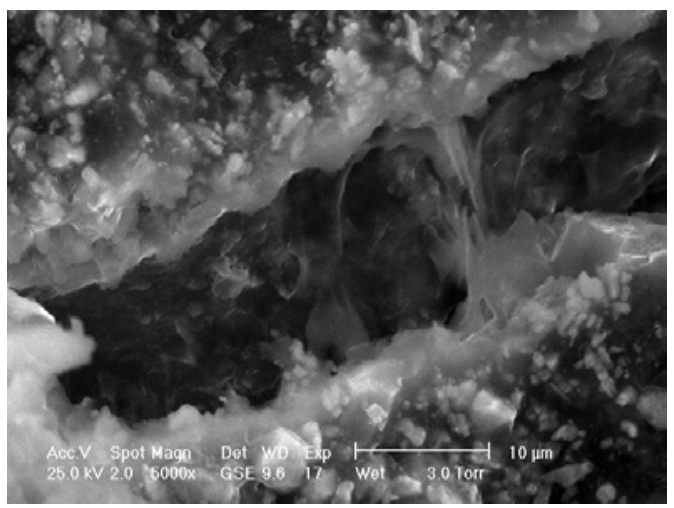

Figure 7. Crack bridging behaviour of polymers in concrete, maximum crack width $\sim 13 \mu \mathrm{m}$

This investigation technique provides spectacular features for the study of hydration and hardening reactions, and for the study of material phase interactions.

\subsection{Results and expectations of 11th ICPIC}

Some novelties and significant progresses, reported at the 11th ICPIC in Berlin, are discussed here. The paper number refers to the reference number of the paper in the proceedings [1].

Two fundamental research topics of the 11th ICPIC are the study of mortars modified with watersoluble polymers and that of hardener-free epoxy-modified mortars. Knapen et al. discuss in paper 11 [13] the problems that are generated by the presence of surfactants at the surface of polymer particles in polymer dispersions. The cement hydration is retarded and the polymer film formation is disturbed. Furthermore, the surfactants cause an excessive air entrapment during mixing. One of the major advantages of water-soluble polymers is the absence of surfactants. The polymer molecules are supplied on a molecular scale, improving the approximation of the relatively large cement grains by the polymers. Film formation on the hydrate crystals may proceed more easily and a lower amount of polymers may be needed to modify mortars. The second topic is studied by Ohama et al. in paper 30 [14], i.e. epoxy-modified mortars without hardener. The authors found that, even without any hardener, epoxy resins are able to harden in the presence of hydroxide ions, produced by the hydration of cement. At ambient temperature, the hardening rate of the hardenerfree epoxy resin is low. It is shown that accelerated curing conditions, e.g. autoclaving or steam curing followed by heat curing, result in a high-strength development.

At the 11th ICPIC, a lot of new applications of concrete-polymer composites are proposed. Knapen et al. (paper 24 [15]) studied the sound absorption by polymer-modified porous cement mortars. Having a high sound absorption coefficient and a high structural strength, these materials can be an alternative for the more conventional sound absorbing materials and contribute to a sustainable construction development and to an improvement of acoustic conditions. Murray discusses the use of preplaced aggregate epoxy concrete for the structural enhancement of deteriorated beams in paper 43 [16]. After removal of the deteriorated concrete and cleaning of the reinforcing steel, the cement concrete is replaced with epoxy concrete with preplaced aggregates. Not only the original load carrying capacity is re-established, also any further corrosion activity is stopped in the repaired section. Dilthey et al. (paper 58 [17]) deal with the possibility to improve 
the technical characteristics of textile reinforced concrete by polymeric impregnation of the rovings and by addition of polymers to the fresh concrete. The impregnation of the rovings improves the tensile strength and strain at failure due to the improved load transmission between the single filaments. This impregnation is combined with polymer modification of the cement concrete itself, increasing the strength of the concrete components even further. Bignozzi et al. consider the reuse of glass waste in polymer mortars in paper 72 [18]. Fine glass fillers are obtained by vitrification of bottom ashes collected from incineration of urban solid wastes or derived from glassy and ceramic fractions obtained by the treatment of separated waste collection. Glass fibres, prepared by drawing waste made glasses, act as reinforcement of the materials. In terms of performance, these new composite materials appear to be promising and competitive with those usually used in the building industry. Further investigations are necessary to verify the environmental sustainability and feasibility of the entire process.

\subsection{Conclusions}

The use of polymers in construction industry is steadily growing. The synergic action of polymers and cement mortar and concrete offers great opportunities for improvement and for a wide range of new and innovative applications. Society and environment require corrective actions to be taken continuously. The use of polymers should be well-considered to guarantee better performance and improved sustainability.

Polymers are no longer special construction materials that replace classical mineral or organic building materials. They are now one vital component in the production of composite and sustainable building materials. They will further allow the development of new and durable constructions, as well as new and durable restoration and retrofitting techniques.

\subsection{Acknowledgement}

The authors would like to thank Prof.Dr.-Ing. Harald Schorn (Technische Universität Dresden) and Dr. Ir. Anne Beeldens (Belgian Road Research Centre) for their cooperation and valuable research.

\subsection{References}

1. Maultzsch, M., editor, Proceedings of 11th Congress on Polymers in Concrete, BAM editions, Berlin, 2004.

2. de Longcamp, M., "Réalités économiques des polymères dans la construction", Proceedings European Colloquium Orgagec '02, 13-15 March 2002, Poitiers, France, Ed. $L C P C$, Paris, 2002.

3. Commission of European Community DG XI, "Financial costs of plastics marking. Final report", August 1999,

Website: http://europa.eu.int/comm/enterprise/construction/index.htm.

4. Plastics Europe, "An analysis of plastics consumption and recovery in Europe 2002\&2003”, 2004.

5. Beeldens, A., Van Gemert, D., Schorn, H., Ohama, Y., "Integrated model for microstructure building in polymer cement concrete", Proceedings of 11th Congress on Polymers in Concrete, Berlin, 2004, pp. 1-10.

6. Beeldens, A., Van Gemert, D., Schorn, H., Ohama, Y., Czarnecki, L., "From microstructure to macrostructure: an integrated model of structure formation in polymer 
modified concrete", RILEM International Journal Materials and Structures, 2004, MS 1715.

7. Beeldens, A., "Influence of polymer modification on the behaviour of concrete under severe conditions", PhD dissertation, Faculty of Engineering, Katholieke Universiteit Leuven, 2002.

8. Beeldens, A., Van Gemert, D., Ohama, Y., Czarnecky, L., "Integrated model of structure formation in polymer modified concrete", Proceedings of the 11th International Congress on the Chemistry of Cement, 11-16 May 2003, Durban, 2003.

9. Ohama, Y., "Handbook of polymer-modified concrete and mortars, properties and process technology", Noyes Publications, 1995.

10. Schorn, H., Schiekel, M., "Shape and distribution of polymer particles in PMC Investigated by Environmental Scanning Electron Microscope (ESEM)", Proceedings (CD-ROM) of the 10th International Congress on Polymers in Concrete (ICPIC), Hawaii, USA, 2001.

11. Tabor, L. J., "Dispersed polymers, revision of concrete society technical report no.9 polymer concrete, chapter 7", Contribution to the Fifth International Congress on Polymers in Concrete at Brighton, UK, 1987, pp. 83-94.

12. Schorn, H., Butler, M., Hempel, S., "Polymers as microcrack stopper in concrete observed in ESEM", Proceedings of 11th Congress on Polymers in Concrete, Berlin, 2004, pp. 11-18.

13. Knapen, E., Beeldens, A., Van Gemert, D., Van Rickstal, F., "Modification of cement concrete by means of polymers in solution", Proceedings of 11th Congress on Polymers in Concrete, Berlin, 2004, pp. 83-90.

14. Ohama, Y., Kumagai, S., Miyamoto, Y., "High strength development through accelerated curings of epoxy-modified mortars without hardener", Proceedings of 11th Congress on Polymers in Concrete, Berlin, 2004, pp. 239-246.

15. Knapen, E., Lanoye, R., Vermeir, G., Lauriks, W., Van Gemert, D., "Sound absorption by polymer-modified porous cement mortars", Proceedings of 11th Congress on Polymers in Concrete, Berlin, 2004, pp. 191-200.

16. Murray, M., "Beam repair with preplaced aggregate epoxy concrete", Proceedings of 11th Congress on Polymers in Concrete, Berlin, 2004, pp. 345-348.

17. Dilthey, U., Mund, F., Raupach, M., Schleser, M., Walk-Lauffer, B., "Improvement of textile reinforced concrete by polymer additives", Proceedings of 11th Congress on Polymers in Concrete, Berlin, 2004, pp. 469-476.

18. Bignozzi, M.C., Saccani, A., Sandrolini, F., "Glass waste valorization in advanced composite materials, Proceedings of 11th Congress on Polymers in Concrete, Berlin, 2004, pp. 587-596. 